\title{
Synthesis of Polyamides by Phosphoroxidation. II. Reaction Conditions
}

\author{
Naoya Ogata and Hozumi Tanaka \\ Department of Chemistry, Sophia University, Chiyoda-ku, Tokyo, Japan.
}

(Received September 20, 1971)

\begin{abstract}
Polycondensation and copolycondensation reactions including the formation of nylon 66 occured at room temperature in the presence of triphenyl phosphite and imidazole to give polyamides in a quantitative yield. Reaction conditions including solvents, temperatures and concentration of monomer and catalysts were investigated. A combination of triphenyl phosphite and imidazole was found to be satisfactory for the polycondensation. The polycondensation reaction may proceed through the formation of a mixed anhydride of carboxylic acid and phosphite, followed by aminolysis by amine. Although the yield of polyamide by this synthetic method was almost quantitative, the inherent viscosity of the product did not exceed more than 0.4. The low morecular weight might be due to a termination reaction, e.g., the formation of phosphite amide.
\end{abstract}

KEY WORDS Polycondensation / Copolycondensation / Phosphoroxidation / Phosphite / Imidazole / Polyamide / Copolyamide /

Polycondensation reactions are usually carried out at temperatures above the melting point of the resulting polymers in order to eliminate volatile products, such as water or alcohol and shift the equilibrium towards the formation of polymer. However, under some conditions, e.g., when an active substituent is introduced into a monomer structure, the reactivity of monomer increases to such a extent that the polycondensation reaction takes place even at room temperature. ${ }^{1}$

It was reported in a previous paper ${ }^{2}$ that polyamide was formed at room temperature by phosphoroxidation in the presence of triphenyl phosphite and imidazole. Various polyamides were prepared by this synthetic method as shown below.

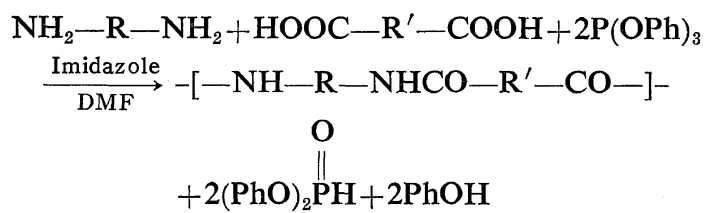

This paper describes our attempts to establish the optimum reaction conditions for the formation of polyamide by modifications of Mitin's method, ${ }^{3}$ the reaction mechanism being also discussed.

\section{EXPERIMENTAL}

Nylon salt prepared from hexamethylenediamine and adipic acid was suspended in dimethylformamide (DMF) with stirring in the presence of triphenyl phosphite and imidazole and the mixture was kept at constant temperatures for the required period.

The suspension started to change gradually and a gel-like polymer was formed. The product was washed with water and then acetone in order to remove unreacted monomers and then dried in a vacuum.

Copolymerization reactions using mixed nylon salts were carried out in a similar manner.

Solution viscosities of the polymers and copolymers were determined in concentrated sulfuric acid $(0.5 \mathrm{~g} / \mathrm{d} l)$ at $30^{\circ} \mathrm{C}$.

\section{RESULTS}

\section{Polycondensation of Nylon 66 Salt}

The rates of polycondensation of nylon 66 salt were determined in DMF solution with a monomer concentration of $0.5 \mathrm{~mol} / l$, triphenyl phosphite $(1.5 \mathrm{~mol} / l)$ and imidazole $(1.5 \mathrm{~mol} / l)$ at various temperatures. The results are shown in Figure 1, where it is seen that at $30^{\circ} \mathrm{C}$ a 


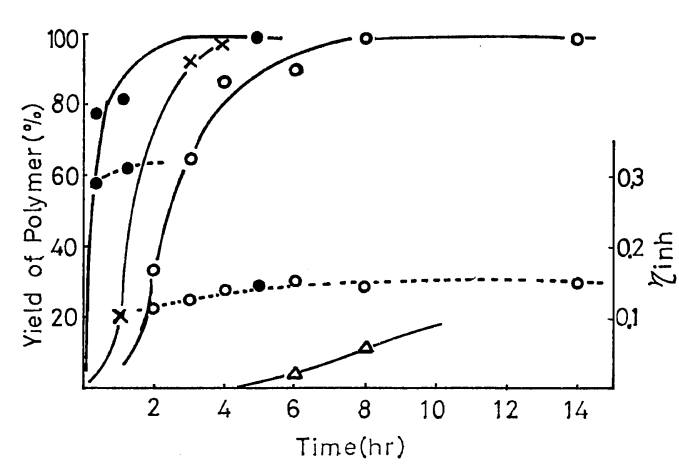

Figure 1. Rate of polycondensation reaction of nylon 66 salt at various temperatures: —, yield of polymer $\left(0,70^{\circ} \mathrm{C} ; \times, 50^{\circ} \mathrm{C} ; \bigcirc, 30^{\circ} \mathrm{C}\right) ; \triangle$, imidazole $\left.\mathrm{g} \mathrm{mol} \%, 30^{\circ} \mathrm{C}\right)$; -..--, $\eta_{\text {inh }}\left(0,70^{\circ} \mathrm{C}\right.$; ○, $\left.30^{\circ} \mathrm{C}\right)$.

Table I. Effect of solvents on the polycondensation reaction ${ }^{\mathrm{a}}$

\begin{tabular}{lrrr}
\hline \multicolumn{1}{c}{ Solvent } & $\begin{array}{c}\text { Time } \\
\text { hr }\end{array}$ & $\begin{array}{c}\text { Yield, } \\
\%\end{array}$ & $\eta_{\text {inh }}$ \\
\hline Dimethylformamide & 43 & 100 & 0.16 \\
Dimethylacetamide & 43 & 100 & 0.16 \\
Dimethyl sulfoxide & 45 & 90 & 0.09 \\
$N$-Methylpyrrolidone & 42 & 85 & 0.19 \\
Triethylamine & 44 & 39 & 0.13 \\
Diisobutylketone & 42 & 11 & 0.15 \\
Acetophenone & 42 & 17 & 0.09 \\
Methyl tolyl keteone & 42 & 22 & 0.09 \\
Tetrahydrofuran & 43 & 81 & 0.17 \\
Dioxane & 42 & 81 & 0.14 \\
Benzene & 44 & 25 & 0.14 \\
$n$-Hexane & 44 & 33 & 0.10 \\
Ethanol & 43 & 0 & - \\
$m$-Cresol & 44 & 0 & - \\
Water & 22 & 0 & - \\
None & 45 & 0 & - \\
\hline
\end{tabular}

a Triphenyl phosphite and imidazole, $3 \mathrm{~mol} / \mathrm{mol}$; monomer concn, $1 \mathrm{~mol} / l$ at $30^{\circ} \mathrm{C}$.

quantitative yield of nylon 66 was obtained within $8 \mathrm{hrs}$. Time dependence on the molecular weight of yielded polymers was not observed when the molar ratios of triphenyl phosphite and imidazole over the monomer were both three. The rate of the polycondensation decreased when the amount of imidazole was decreased to 8 moles per 100 moles of the monomer, as can be seen in Figure 1.

The results of the polycondensation of nylon
66 salt in various solvents are summarized in Table I. Amide solvents such as DMF, dimethylacetamide or $\mathrm{N}$-methylpyrrolidone were found to be suitable for the preparation of polyamides.

The results of the polycondensation reaction of nylon 66 salt in DMF or hexamethylenephosphoramide (HMPA) under various reaction conditions are summarized in Table II. The results indicate that the yield of polyamide decreased with decreasing monomer concentrations and that the molecular weight of the polyamide increased with increasing reaction temperatures. Nylon 66 having a inherent viscosity of 0.32 was obtained in a good yield when the polycondensation was carried out in DMF or HMPA at $70^{\circ} \mathrm{C}$ for one hour.

Polycondensation of nylon 66 salt was carried out in DMF in the presence of various ratios of triphenyl phosphite and imidazole to the monomer; the results obtained are shown in Table III.

Stoichiometric ratio of imidazole was not necessary to form polyamide in a good yield. Polyamide was obtained in an almost quantitative yield even when the amount of imidazole was only 8 mole per mole of the monomer. The yield of polyamide decreased markedly in the absence of imidazole. On the other hand, the concentration of triphenyl phosphite could be

Table II. Polycondensation of nylon 66 salt under various conditions ${ }^{a}$

\begin{tabular}{|c|c|c|c|c|c|}
\hline \multirow[b]{2}{*}{ Solvent } & \multirow{2}{*}{$\begin{array}{c}\text { Mono- } \\
\text { mer } \\
\text { concn, } \\
\mathrm{mol} / l\end{array}$} & \multirow{2}{*}{$\underset{{ }^{\circ} \mathbf{C}}{\text { Temp, }}$} & \multirow{2}{*}{$\underset{\mathrm{hr}}{\text { Time }}$} & \multicolumn{2}{|c|}{ Polymer } \\
\hline & & & & $\underset{\%}{\text { Yield, }}$ & $\eta_{\text {inh }}$ \\
\hline \multirow{9}{*}{ DMF } & 0.125 & 30 & 6 & 17 & 0.13 \\
\hline & 0.25 & 30 & 6 & 78 & 0.22 \\
\hline & 0.50 & 30 & 6 & 90 & 0.14 \\
\hline & 1.00 & 30 & 6 & 100 & 0.20 \\
\hline & 0.50 & 50 & 3 & 92 & 0.25 \\
\hline & 0.50 & 70 & 1 & 81 & 0.32 \\
\hline & 0.50 & 70 & 5 & 80 & 0.14 \\
\hline & 0.25 & 70 & 5 & 91 & 0.32 \\
\hline & 0.50 & 70 & $1 / 3$ & 78 & 0.29 \\
\hline \multirow{2}{*}{ HMPA } & 0.50 & 30 & 39 & 100 & 0.22 \\
\hline & 0.50 & 50 & 1 & 98 & 0.30 \\
\hline
\end{tabular}

a Triphenyl phosphite and imidazole, $3 \mathrm{~mol} / \mathrm{mol}$.

Polymer J., Vol. 3, No. 3, 1972 
Synthesis of Polyamides by Phosphoroxidation. II. Reaction Conditions

Table III. Effect of catalyst concentration on the polycondensation ${ }^{a}$

\begin{tabular}{lccrrr}
\hline $\begin{array}{l}\text { Triphenyl } \\
\text { phosphite, } \\
\text { mol/mol }\end{array}$ & $\begin{array}{c}\text { Imida- } \\
\text { zole, } \\
\text { mol/mol }\end{array}$ & $\begin{array}{c}\text { Temp } \\
{ }^{\circ} \mathrm{C}\end{array}$ & $\begin{array}{c}\text { Time, } \\
\text { hr }\end{array}$ & $\begin{array}{c}\text { Yield, } \\
\%\end{array}$ & $\eta_{\text {inh }}$ \\
\hline 3.0 & 0 & 30 & 44 & 18 & 0.07 \\
3.0 & 0.08 & 30 & 43 & 98 & 0.15 \\
3.0 & 0.40 & 30 & 43 & 84 & 0.07 \\
3.0 & 0.80 & 30 & 43 & 87 & 0.15 \\
3.0 & 1.52 & 30 & 45 & 94 & 0.17 \\
3.0 & 3.04 & 30 & 43 & 100 & 0.16 \\
4.0 & 3.04 & 30 & 44 & 114 & 0.13 \\
3.04 & 3.04 & 70 & 5 & 100 & 0.17 \\
1.0 & 3.04 & 30 & 44 & 96 & 0.15 \\
0.68 & 3.04 & 30 & 44 & 60 & 0.10 \\
0 & 3.04 & 30 & 44 & 0 & - \\
1.0 & 0.08 & 70 & 5 & 53 & 0.12 \\
\hline
\end{tabular}

a Monomer concn $=0.5 \mathrm{~mol} / l$ in DMF.

Table IV. Effect of bases on the polycondensation $^{b}$

\begin{tabular}{lccc}
\hline \multicolumn{1}{c}{ Base $^{\mathrm{a}}$} & Time, $\mathrm{hr}$ & Yied, $\%$ & $\eta_{\text {inh }}$ \\
\hline Imidazole & 43 & 100 & 0.16 \\
Pyridine & 44 & 33 & 0.06 \\
Triethylamine & 44 & 4 & - \\
$\mathrm{KOH}$ & 45 & 0 & - \\
$\mathrm{H}_{3} \mathrm{PO}_{4}$ & 45 & 0 & - \\
None & 44 & 18 & 0.07
\end{tabular}

a Amount of base, $3 \mathrm{~mol} / \mathrm{mol}$; triphenyl phosphite, $3 \mathrm{~mol} / \mathrm{mol}$.

b Monomer concn, $1 \mathrm{~mol} / \mathrm{l}$ in DMF at $30^{\circ} \mathrm{C}$.

reduced to an equal molar ratio and still obtain polyamide in a quantitative yield. The yield of polyamide decreased when the amount of triphenyl phosphite was reduced to less than one mole per mole of the monomer, and polyamide was not formed at all without the addition of triphenyl phosphite, (seen Table III). The effect of several bases on the polycondensation reaction was investigated and the results are shown in Table IV. It is seen that only imidazole had a strong effect on the formation of polyamide while other bases yielded polyamide in a very poor yield.

The effect of various phosphites on the polycondensation reaction is summarized in Table V. Aromatic phosphite had a strong catalytic effect, while no reaction occured in the presence
Table V. Catalytic effect of phosphites or phosphate on the polycondensation ${ }^{a}$

\begin{tabular}{|c|c|c|c|c|}
\hline \multicolumn{2}{|c|}{ Phosphorous compound } & \multirow{2}{*}{$\underset{\mathrm{hr}}{\mathrm{Time}}$} & \multirow{2}{*}{$\underset{\%}{\text { Yield, }}$} & \multirow{2}{*}{$\eta_{\text {inh }}$} \\
\hline Kind & $\mathrm{mol} / \mathrm{mol}$ & & & \\
\hline & 3.04 & 43 & 100 & 0.16 \\
\hline & 3.04 & 45 & 85 & 0.15 \\
\hline $\mathrm{P}\left(\mathrm{OC}_{2} \mathrm{H}_{5}\right)_{3}$ & 3.04 & 43 & 12 & - \\
\hline & 3.04 & 44 & 0 & - \\
\hline & 3.04 & 46 & 0 & - \\
\hline $\mathrm{H}_{3} \mathrm{PO}_{4}$ & 3.04 & 46 & 0 & - \\
\hline None & 0 & 44 & 0 & - \\
\hline & 3.04 & 44 & 0 & - \\
\hline
\end{tabular}

a Monomer concn, $1 \mathrm{~mol} / \mathrm{l}$ in $\mathrm{DMF}$ at $30^{\circ} \mathrm{C}$; Imidazole, $3.04 \mathrm{~mol} / \mathrm{mol}$.

of alkyl phosphite or phosphate. Although no definite conclusion can be deduced from this result, the valency change from trivalent to pentavalent phosphorous atoms seems to play a role as a driving force to cause the polycondensation.

\section{Copolycondensation}

Copolycondensation of various nylon salts was carried out at various molar ratios of two kinds of nylon salts in DMF at $70^{\circ} \mathrm{C}$ in the presence of three moles of triphenyl phosphite and imidazole. The medium was almost homogeneous in the range of molar ratios between $7 / 3$ and $3 / 7$, although it was not completely clear with a gel-like swollen polymer. Results of the copolycondensation are summarized in Table VI.

Generally speaking, inherent viscosities of the resulting copolyamides were highest at the molar ratio of $5 / 5$ in the feed and the yields of copolyamide from $\alpha, \alpha, \alpha,{ }^{\prime} \alpha^{\prime}$-tetramethyladipic acid were low among the copolycondensation reactions.

\section{DISCUSSION}

It was found in this investigation that polycondensation reaction between diamine and dicarboxylic acid takes place at a relatively low 
Table VI. Copolycondensation of nylon salts at $70^{\circ} \mathrm{C}^{\mathrm{a}}$

\begin{tabular}{|c|c|c|c|c|c|}
\hline \multicolumn{2}{|c|}{ Nylon salt } & \multirow{2}{*}{$\begin{array}{c}\text { Molar } \\
\text { ratio, } \\
\text { A/B }\end{array}$} & \multirow{2}{*}{$\underset{\mathrm{hr}}{\mathrm{Time}}$} & \multirow{2}{*}{$\begin{array}{c}\text { Yield, } \\
\%\end{array}$} & \multirow{2}{*}{$\eta_{\text {inh }} \mathrm{mp},{ }^{\circ} \mathrm{C}$} \\
\hline A & B & & & & \\
\hline \multirow{7}{*}{6.4} & \multirow{7}{*}{6.10} & $1 / 9$ & 5 & 94 & $0.25220-224$ \\
\hline & & $3 / 7$ & 5 & 90 & $0.34 \quad 196-198$ \\
\hline & & $4 / 6$ & 5 & 88 & $0.31203-205$ \\
\hline & & $5 / 5$ & 2 & 86 & $0.33215-223$ \\
\hline & & $5 / 5$ & 5 & 86 & $0.25216-220$ \\
\hline & & $6 / 4$ & 5 & 85 & $0.25241-245$ \\
\hline & & $8 / 2$ & 5 & 79 & $0.15256-260$ \\
\hline \multirow{7}{*}{6.4} & \multirow{7}{*}{6.6} & $1 / 9$ & 5 & 88 & $0.28 \quad 254-255$ \\
\hline & & $3 / 7$ & 5 & 97 & $0.26236-238$ \\
\hline & & $4 / 6$ & 5 & 84 & $0.26238-240$ \\
\hline & & $5 / 5$ & 2 & 90 & $0.30228-235$ \\
\hline & & $5 / 5$ & 5 & 85 & $0.32231-236$ \\
\hline & & $6 / 4$ & 5 & 80 & $0.23 \quad 255-258$ \\
\hline & & $8 / 2$ & 5 & 86 & $0.17261-265$ \\
\hline \multirow{7}{*}{6.6} & \multirow{7}{*}{6.10} & $1 / 9$ & 5 & 92 & $0.28 \quad 215-217$ \\
\hline & & $3 / 7$ & 5 & 92 & $0.32 \quad 207-209$ \\
\hline & & $4 / 6$ & 5 & 94 & $0.25205-211$ \\
\hline & & $5 / 5$ & 2 & 88 & $0.37200-205$ \\
\hline & & $5 / 5$ & 5 & 95 & $0.34 \quad 207-211$ \\
\hline & & $6 / 4$ & 5 & 94 & $0.34225-230$ \\
\hline & & $8 / 2$ & 5 & 93 & $0.32246-248$ \\
\hline \multirow{7}{*}{6.6} & & $1 / 9$ & 5 & 53 & $0.17182-184$ \\
\hline & $\alpha, \alpha, \alpha,{ }^{\prime} \alpha^{\prime}$ & $3 / 7$ & 5 & 49 & $0.19147-151$ \\
\hline & Tetramethyl- & $1-4 / 6$ & 5 & 62 & $0.16126-130$ \\
\hline & adipic acid & $5 / 5$ & 5 & 66 & $0.21218-224$ \\
\hline & & $6 / 4$ & 5 & 72 & $0.22225-231$ \\
\hline & & $8 / 2$ & 5 & 72 & $0.14243-248$ \\
\hline & & $5 / 5^{b}$ & 40 & 75 & $0.14217-223$ \\
\hline
\end{tabular}

${ }^{a}$ Monomer concn, $0.5 \mathrm{~mol} / l$ in DMF; triphenyl phosphite and imidazole, $3.04 \mathrm{~mol} / \mathrm{mol}$.

b Reaction was carried out at $30^{\circ} \mathrm{C}$.

temperature in the presence of triphenyl phosphite and imidazole to give polyamide in a quantitative yield, and the reaction conditions for obtaining polyamide and copolyamide were established.

The polycondensation reaction might proceed through a mixed anhydride from a carboxylic acid and phenyl phosphite, and the intermediate may undergo aminolysis, forming an amide.

$$
\begin{aligned}
& \mathrm{R}-\mathrm{COOH}+(\mathrm{PhO})_{3} \mathrm{P} \\
& \stackrel{\text { Imidazole }}{\longrightarrow} \mathrm{R}-\mathrm{COOP}(\mathrm{OPh})_{2}+\mathrm{PhOH} \\
& \mathrm{R}-\mathrm{COOP}(\mathrm{OPh})_{2}+\mathrm{R}^{\prime}-\mathrm{NH}_{2} \\
& \stackrel{\mathrm{R}-\mathrm{CONH}-\mathrm{R}^{\prime}+(\mathrm{PhO})_{2} \mathrm{POH}}{\longrightarrow}
\end{aligned}
$$

This reaction scheme was confirmed by the following experiment. When one mole of adipic acid was made to react with two moles of triphenyl phosphite in the presence of imidazole in tetrahydrofuran, two moles of phenol was found in the solution, (gas chromatography). A crystalline product isolated from the solution suggested the structure of the mixed anhydride.

$$
\begin{gathered}
\mathrm{HOOC}\left(\mathrm{CH}_{2}\right)_{4} \mathrm{COOH}+2(\mathrm{PhO})_{3} \mathrm{P} \\
\stackrel{\text { Imidazole }}{\longrightarrow}(\mathrm{PhO})_{2} \mathrm{POOC}\left(\mathrm{CH}_{2}\right)_{4} \mathrm{COOP}(\mathrm{OPh})_{2} \\
+2 \mathrm{PhOH}
\end{gathered}
$$

This isolated anhydride could react with hexamethylenediamine to form polyamide in a quantitative yield. The formation of the anhydride was accelerated in the presence of imidazole.

Triphenyl phosphate $(\mathrm{PhO})_{3} \mathrm{P}=\mathrm{O}$ did not react with a carboxylic acid and a trivalent phosphorous atom is necessary to cause the reaction. However, triethyl phosphite did not react with a carboxylic acid, and the difference in reactivity between aromatic and aliphatic phosphites might be attributed to the acid strength of dialkyl phosphite $(\mathrm{RO})_{2} \mathrm{POH}$.

It is known that dialkyl phosphite is in equilibrium with pentavalent dialkyl phosphite which cannot form a mixed anhydride with a carboxylic acid.

$$
(\mathrm{RO})_{2} \mathrm{P}-\mathrm{OH} \rightleftharpoons(\mathrm{RO})_{2} \stackrel{\mathrm{P}}{\mathrm{O}}-\mathrm{H}
$$

Therefore, it might be necessary to shift the equilibrium toward the pentavalent phosphorous atom to proceed the condensation reaction with amine since dialkyl phosphite is liberated by the condensation reaction. The role of imidazole on the reaction is not yet clear.

Generally speaking, molecular weights of condensation polymers are correlated with polymer yields. The inherent viscosity of resulting polyamide did not exceed more than 0.4 and no exact correlation between yield and molecular weight of polyamide was apparently observed since the inherent viscosity of polyamide did not increase with time as shown in Figure 1. This result suggests that a termination reaction takes place to stop the growth of polyamide during the reaction and the reaction proceeds 
Synthesis of Polyamides by Phosphoroxidation. II. Reaction Conditions

not through a simple step-growth polycondensation but through an exchange reaction with a mechanism different from condensation, involving intermediate products.

After the polycondensation reaction of nylon 66 salt apparently completed under optimum reaction conditions, another fresh triphenyl phosphite and imidazole were added to the solution and the reaction was continued for another one day. The inherent viscosity of resulting polyamide did not increase at all. Thus, the apparent termination reaction is not due to the deactivation of catalysts.
Further studies on the reaction kinetics including termination reaction are necessary, which will be reported in a later paper.

\section{REFERENCES}

1. N. Ogata, J. Polym. Sci., Part C, 31, 217 (1970).

2. N. Ogata and H. Tanaka, Polymer J., 2, 672 (1971).

3. Yu. V. Mitin, et al., Tetrahedrons Letters, 5267 (1969).

4. C. G. Overberger, R. A. Veneski, and Jan Šebenda, J. Polym. Sci., Part A-1, 9, 701 (1971). 